\title{
Constraints and Facilitators for Successful Integration: How Bureaucratic Contacts Affects Migrants' Pathways
}

\author{
Warda Belabas ${ }^{1}$, Lasse Gerrits ${ }^{2}$ \\ ${ }^{1}$ Erasmus University Rotterdam, Rotterdam, the Netherlands \\ ${ }^{2}$ Otto-Friedrich University Bamberg, Bamberg, Germany \\ Correspondence: Warda Belabas, Erasmus University Rotterdam, Rotterdam, the Netherlands.
}

Received: March 31, 2017

doi:10.11114/ijsss.v5i7.2496
Accepted: May 22, $2017 \quad$ Available online: June 19, 2017

URL: https://doi.org/10.11114/ijsss.v5i7.2496

\begin{abstract}
Integration of migrants in Dutch society is a continuous political concern. The regulations governing the immigrant integration processes, and the formal demands to the migrants have been revised several times. Inevitably, the process requires the immigrant to engage in bureaucratic contacts. We postulate that these bureaucratic contacts have a reinforcing or a dampening effect on the integration process, hence on its success. We deployed a grounded research approach in order to investigate this assumption. Semi-structured qualitative interviews were conducted with 51 migrants. We conclude that bureaucratic contacts have considerable impact on many aspects of the migrants' lives. The observed patterns of positive and negative loops with both favorable and unfavorable consequences for migrants demonstrate the systematic reality in which integration processes develop. The bureaucratic contacts - or lack thereof are constantly used by migrants to evaluate their situation and to decide on new actions. This in turn sets off a chain reaction that impacts both bureaucratic contacts later on and the way migrants integrate in Dutch society.
\end{abstract}

Keywords: migration, integration, complex systems, bureaucratic contacts, feedback loops

\section{Introduction and Motive}

The perceived successes or failures of migrant integration in Dutch society is a continuous concern of politicians and policy-makers. Consequently, the relevant regulations and the formal demands to migrants have been revised several times over the past decades (e.g. Penninx Garcés-Mascarenas \& Scholten, 2006; Vasta, 2007; Entzinger, 2006). These changes signal attempts to find an all-encompassing administrative system to deal conclusively with all types of migrants. Immigrants all have very di verse backgrounds and motives for migrating to a country such as the Netherlands. In the process, they will inevitably engage in bureaucratic contacts, in particular when admitted to the country. Central to this regulatory system is the classification of immigrants in certain categories, e.g. asylum seekers or family members reuniting with their families. Each category is linked to distinct sets of bureaucratic procedures. The legal obligations, the possibilities for education and for work all depend on this categorization.

As elsewhere in Europe (e.g. Joppke, 2007), recent policy debates centered the perceived failure of immigrants to successfully blend in the Dutch society (Scholten \& van Nispen, 2008). This perceived failure is often attributed to immigrants' unwillingness to adapt to their new situation. Consequently, newer policies have a stronger focus on punishment and reward for achieving integration. However, we postulate that the extent of successful integration can be traced back to patterns of interactions between immigrants and bureaucracy rather than just the willingness at the current moment. While most literature focuses on the attributes of individual immigrants, the local conditions under which they integrate matters considerably (see e.g. Berry, 1997; Berry Phinney Sam \& Vedder, 2006; Crul \& Schneider, 2010; Kasinitiz Mollenkopf Waters \& Holdaway, 2008; Koopmans, 2003). In this paper, we will focus on the effects of the interactions between immigrants and bureaucrats on the extent of integration. We will do this in terms of feedback loops.

Our postulate stems from a systemic understanding of immigration and integration. In this view, immigration and integration are heavily contextualized phenomena that are subject to feedback loops. This point of departure helps understanding why the simplistic cause-and-effect relationships as assumed by current policies are only marginally successful. Therefore, our research question is: what effect do series of bureaucratic contacts have on the integration of immigrants in the Netherlands? 
We will first outline our theoretical approach. It is rooted in systems' theory, from which follows a grounded research approach in order to map the elements and causal structure of immigration and integration. This culminates into a more detailed overview on how we have structured our data and how we conducted the analysis. We will present our empirical findings in subsequent sections, with a focus on the systemic nature of the issue and the feedback loops that arise from interaction between migrants and bureaucracy. Finally, we present the patterns discovered and the conclusions that can be derived from those patterns.

\section{Research Methods}

Central to our research approach is the idea that immigrants engage in a series of bureaucratic contacts over a longer time span. These contacts constitute feedback loops that may reinforce (i.e. positive feedback) or dampen (i.e. negative feedback) integration attempts. Since integration processes - to our knowledge - have not yet been analyzed in terms of feedback loops, we need to deploy an inductive research approach.

Feedback loops are strongly contextual (e.g. Byrne \& Ragin, 2009). Understanding the interaction between migrants and bureaucracy requires understanding of the particular settings in which the interaction takes place (cf. Byrne, 2005). In other words: each observed instance shows a specific assembly or configuration of generic elements or properties (i.e. something that appears elsewhere in similar cases) and specific elements or properties (i.e. something that only occurs in this particular instance) (ibid.) It means that observations of causal relationships are specific to certain situations because they are formed by the interaction between generic developments and local conditions (Buijs, Eshuis \& Byrne, 2009; Mjøset 2009).

In addition to this contextual nature, we need to point out that semiotics matter in understanding feedback loops (Churchman, 1979; Ulrich, 1988; Checkland, 1981; Flood, 1999a). Feedback loops are established through the mental models of people who try to understand the systemic whole they find themselves in and the consequent actions they undertake to reach their goals (e.g. Clark \& Crossland, 1985). It implies that immigrants and bureaucrats build a mental model of the system they find themselves in, which helps them to arrive at decisions to undertake a certain action. For example, an immigrant may reason "I have a better chance of finding a good job and getting help with that, when my integration counselor sees that I'm doing everything in my power to learn Dutch". This constitutes a mini-theory (e.g. Wagenaar, 2007). In undertaking this action, they in fact further define the systemic whole and confirm its operation.

In the present study, such feedback loops are based on the occurrence and nature of the bureaucratic contacts that alter or reconfirm the situation of the migrants and their subsequent behavior. In other words: following the intention and actions of the migrants, the contacts may bring about a change or lack thereof in the situation of the migrants. Both outcomes can be perceived favorably or unfavorably by the migrants, which is important in understanding their subsequent actions. Sometimes, loop effects can also be based on the expectations that something will work out in a certain way, upon which the expectation is responded on with a corrective action, i.e. without an actual contact between bureaucrat and migrant.

The gist of these points of departure is that the research had to follow an inductive, grounded method (see e.g. Straus s \& Corbin, 1990). The presented thoughts and findings in this study are hence the result of "a continuous interplay between analysis and data collection" (Strauss \& Corbin, 1994: p.273). Firstly, because such an approach allows researchers to systematically extract causal (feedback) structures from interview data, in our case: these causal structures helped us to reconstruct the subjective mental models of migrants living in the Netherlands. People assign very different meaning to the world that they experience, and decisions or actions follow the logic of these subjective perceptions of reality. Following Kim \& Andersen (2012), we believe that making these mental models more explicit, is indispensable in explaining and understanding system behaviors and thus in improving policy-making. Grounded research fits the interpretative nature of system dynamics, because it allows for the discovery of concepts and their relationships from raw data (ibid.).

Secondly, uncovering mental models forces one to look beyond exogenous factors. It shifts the focus to what Forrester calls "endogenous dynamics" (Richardson, 2011). It allowed us to generate insight in the feedback loops, thus in explaining the success or failure of immigrant integration and even in understanding the sometimes counterintuitive and unpredictable workings of public policies, which too often are based in mental models that are "static, narrow and reductionist" (Sterman, 2006). In order to go beyond the truism that - like many other policy issues - immigration and integration are complex, we argue that such a grounded method approach is more than needed, especially because there are very few articles that "have been related to elicitation of mental models and its empirical rigor" (Kim \& Anderson, 2012: 313).

On an operational level, this approach called for semi-structured interviews around a set of topics. We sampled 51 respondents, divided in two categories. The first category concerned migrants who had arrived and settled in the Netherlands under previous legal regimes, the group of so-called oudkomers ('already arrived') in policy jargon. Data 
from this group allowed us to assess the long-term impact of bureaucratic contacts because those immigrants had settled in the Netherlands for decades. The second group concerned migrants who had recently arrived and were subject to the current legal regime, the so-called nieuwkomers ('newly arrived'). Data from this group allowed us to tap into the fresh experience of migration and the changes between the home country and host country.

Most respondents were found through a large educational institution where they followed integration courses. We sent a general call for participation to a contact person at the institution. She dispersed the call among potential respondents and we contacted those willing to be interviewed. In addition, some respondents were approached through our perso nal network. Through snowballing, the migrants that we personally knew brought us into contact with more respondents. We minimized sample-selection bias by utilizing several different networks of individuals. Subsequently we selected on diversity in origins and motives for migration. 'Diversity in origins' was subdivided into the following three themes: perceived socio-economic status, education, and occupation. The respondents were coming from 21 countries: Morocco (11), China (6), Turkey (4), Iran (2), Poland (2), Portugal (2), Thailand (2), Vietnam (2), Afghanistan (2), Albania (1), Argentina (1), Bangladesh (1), Bulgaria (1), Cape Verde (1), Ghana (1), India (1), Italy (1), Malaysia (1), Pakistan (1), Somalia (1), and South Korea (1). A number of respondents came to the Netherlands via an intermediary country: Cape Verde (two via Italy and one via Portugal), Algeria (via Spain), Colombia (via Spain), and Peru (also via Spain). A full list of the respondents and their personal details are available from the authors upon request.

Most of the interviews were conducted in Dutch; a smaller number was conducted in English, Berber or Arabic. One of the authors speaks both English and Berber, so that most of the interviews could be conducted by the authors themselves. In the case of three Arabic speaking respondents, it was necessary for an interpreter to be present. After each of the interviews, we reflected with her on the respondent's story in order to ensure a common understanding of that story. Interviews were then transcribed, and translated to Dutch by the researchers if necessary.

The data was open coded, using AtlasTI, in order to exhaustively map the various occurrences, events, processes, and behavior in relation to bureaucratic contacts. The data were re-coded over a number of interviews to improve accuracy (e.g. Berg \& Lune, 2004). The coding of data allowed it to be systemically related, e.g. that some piece of data was found to 'be part of the other' or 'occur in the context of', or other such groupings. Although in itself coding doesn't generate an interpretation, it helped us to rethink the data and to arrive at interpretations. In particular AtlasTI, a technique of computer-assisted qualitative data analysis, has facilitated us in developing such interpretations. The interviews focused in particular on the following topics: a) what the lives of the migrants were back in the countries of origin b) how they lived their lives now (in the host society) c) which bureaucratic contacts they encountered, and d) how these bureaucratic contacts affected their lives. The topic-list as used by the researchers is available upon request. We attempted to create a comfortable situation in which respondents felt free and safe to share their stories. Therefore we started the interview by asking the respondent to first tell us something about his or her home country and the type of life he/she was living. Using the data, we reconstructed the individual pathways of the migrants according to their characteristics and the steps they had undertaken when moving from the country of origin to settling in the Dutch context. The resulting patterns are discussed in the next sections.

\section{History of Immigrant Policy in the Netherlands}

The Dutch approach to immigrant integration in society has been labeled the 'multi-cultural approach', for which it has gained much attention (Duyvendak \& Scholten, 2011). Central to this approach was the belief that recognition and accommodation of cultural, ethnic and religious diversity would lead to successful emancipation of immigrants into society. But more recently, immigration and integration policies have undergone major changes. It was only in the early 1980s that the Dutch government developed an actual policy for immigrant integration. This was because of the realization that migrants were going to stay permanently instead of temporarily as was always assumed. Integration policies in this period were targeted at specific ethnic minorities and tried to improve their social-economic position in particular by stimulating them in preserving their cultural identities.

The 1990s brought a change of thought: social-economic participation of immigrants was now put at the heart of the new policy, "by stimulating individual migrants to live up their civic rights as well as their duties and to become economically independent participants in society" (Poppelaars \& Scholten, 208: 340). Preceded by a heated national debate about the perceived failure of 'the multicultural society', even greater changes took place in the Dutch integration policy after the turn of the millennium. Led by populist politician Fortuyn, the perceived failure of migrants to integrate 'properly' became one of the central political issues. In addition: preserving cultural identities of immigrants was now considered a hindrance to integration and abiding to basic Dutch norms became the standard. The Netherlands is a good example of a Western nation-state that replaced its multicultural policy of the 1990s and mid-1990s by a policy aimed at individual integration. Since 2006, the obligations of immigrants have become stricter, for example regarding the exams that certain types of migrants have to pass in the country of origin before they can apply for a 
residence permit. Migrants are expected to take a much greater responsibility in order to successfully integrate into the Dutch society (Boom, Weltevrede, Seidler, Wensveen, Snel \& Engbersen, 2010).

A consequence of the shifts in the integration approaches is that the question of what 'integration' exactly entails is constantly subject to change. In addition, 'integration' itself is a very multi-layered concept with many different meanings. Entzinger \& Biezeveld (2003), for example, argue that one should at least make a distinction between the institutional and the normative dimension of integration: "The former refers to an increase in immigrant participation in the major institutions of a society (e.g. labor market, education and health care system), the latter to changes in the immigrants' cultural orientation and identification (ibid, p.8)." Following Benish-Weisman \& Horenczk (2010) this study proposes an emic conceptualization and measurement of 'integration', which assesses both constructs in terms of the immigrant's own criteria and not according to standardized external parameters. 'Successful integration' is hence conceptualized in terms of perceived success, as this is something that suits well with the grounded approach we followed. Following Korac (2003), we argue that such an approach is necessary because the majority of studies on migrant settlement tend to use a 'top-down' perspective on the concept of 'integration', which reflects in the lack of taking in account perceptions of immigrants on what integration is and how it is actually facilitated or counteracted. This is problematic, because migrant experiences are proved a significant indicator for adaptation to the new society (Montgomery, 1996). Consequently, the latter author contends that "more thought should be devoted to the distinction (self-report or perceived measures) and objective adjustment" (ibid, p. 696). As the data below will show us, self-reported integration can both involve feelings of belonging to place and people in the new society, as well as professional achievement, acquiring status and economic independence.

\section{Diversity among Immigrants}

Naturally, immigrants constitute a highly diverse group of people. Each respondent had a very personal and unique story to tell. This diversity concerned their backgrounds, their motives for moving to the Netherlands, the way they were approached by bureaucrats, the rules and regulations they had to comply to and the situation they now found themselves in. The differences in origins and current situation may be self-explanatory, but the bureaucratic diversity deserves some explanation.

The first difference is in the shifts in policies over the years, as already discussed above. Previous regimes were more relaxed regarding the obligations of immigrants, e.g. to follow certain courses or to have someone vouch for them. More recent policies are much stricter due to contemporary understanding that immigration is a permanent social process. A second difference is in the legal obligations. For example, an EU citizen is free to move in or out of the country without many bureaucratic hurdles but for a non-EU citizen, things are more complicated. The third difference is in the willingness of bureaucrats to use their discretion to make a decision that is tailored to the immigrants' situation (see e.g. Belabas \& Gerrits, 2016). Lipsky (1980), for example, argues that bureaucrats always have this discretion wherever the effective limits on his power leaves him free to make a choice among possible courses of action and inaction. The fourth difference concerns the immigrants' willingness to comply. Despite heavy regulations and associated fines, it still happens that immigrants chicane around certain obligations. We took these differences into account when reconstructing the feedback loops.

\section{Pathways of Immigration}

All immigrants have gone through specific pathways when trying to establish life in the Netherlands. Using the data, we reconstructed specific immigration and integration pathway for each respondent. We then used the diagrams to identify archetypical feedback loops. Whilst it is impossible to explain each individual occurrence in this text, we want to highlight three exemplary pathways first in order to give readers an understanding of the diversity we encountered.

The first example is of an Iranian refugee, who arrived in the Netherlands in 1995. Being a political activist against the ruling regime meant that her safety and that of her family was no longer guaranteed. However, the decision to migrate was difficult because of what she had to leave behind: family members and friends, a well-paid job and a good home. Once arrived in the Netherlands, the first contacts with the Dutch authorities made her realize that she had to start all over. The (often repeated) interviews with officials working at the Center for Refugees were experienced as stressful and emotionally draining. The continuous transfer between various Refugee Centers reinforced this negative impact on her emotional wellbeing and that of her family. On top of that, the Centers counselor put pressure on her to find a job immediately. In conversations with her, he emphasized that in the new society it was expected from her that she found a job as soon as possible and that "there was no time to waste", meaning: she should accept jobs that in no way reflected her professional accomplishments. Whilst she preferred to learn the language first, she eventually accepted a low-skilled job at a factory.

This type of contact, with an advisor at the Center for Refugees, was mentioned more often. It appears to have a great impact on the life of the migrants who followed this pathway. In this particular case: the choice to focus on work and 
not on learning the language made it harder for the migrant to be eligible for high-skilled work. After a couple of years, she decided to search for a better job. In the meantime, she also had undertaken action by completing several courses (e.g. to improve her computer skills) that could increase the chance to find a high-skilled job. She applied for one that matched her degrees and professional experience. Whilst the prospective employer was very enthusiastic about her profile, she wasn't qualified for the job because her language skill was insufficient. Also, her diplomas obtained in Iran were not recognized by the Dutch authorities. After several attempts she gave up and kept working at the factory. This situation impacted her financial condition, happiness and health conditions. Many years of factory work caused a back injury and she still needs to undergo treatment. As a result of her disappointing experiences, she developed an aversion and mistrust towards Dutch bureaucracy.

The second example concerns a Moroccan couple, who migrated in the late 1970s. This was mainly for economic reasons. They were not extremely poor but life in the Moroccan countryside was exhausting. The male respondent migrated first. His first contact with the Dutch government was with the Immigration Department in order to obtain a residence permit. After filling in several documents - with help of friends who migrated before - he gained his residence permit quickly. Shortly after, the migrant was obliged to participate in a health test, carried out by a local health agency. After that, he had hardly any contact with the authorities. No substantial demands were placed on his residence. He quickly found a job in a factory, with help of the same friends.

He applied for family reunification after a couple of years. With help of his employer he migrated his wife and child to the Netherlands within a couple of weeks. None of them was obliged to learn Dutch or to gain knowledge about Dutch society. The focus on 'work' instead of 'learning' impacted the life of this family significantly because they developed little understanding of the Netherlands. They found it difficult to fill in tax forms or to understand how things worked at their child's' school. They also had little knowledge of their rights and obligations towards the government or their employer. The respondent worked 16 hours a day without knowing that labor law forbade this. It was only 5 years ago that municipal authorities send an official letter to say that they were obliged to participate in a civic integration course. While this demand is a consequence of policy changes, they were not willing to participate. According to them, the Dutch government has no right to demand anything from them, given the fact that they have never invested in them in the first place.

The third example concerns a Moroccan migrant, who migrated more recently (in 2009) because of family reunification. Under the then-current regime, the emphasis is on mastering the language prior to arrival in the Netherlands. The Integration Abroad Act requires migrants to take an exam about knowledge of the Dutch language and society before being eligible for a residence permit. This respondent's first bureaucratic contact therefore took place before departure from Morocco. Because of the legal requirements regarding her income, employment and living situation, his wife filled out numerous documents in order to vouch for him. When they finished the procedure, he registered for the so-called 'Basic Integration Examination'. He experienced the period prior to the exam as very stressful because he knew how much depended on it. He spent months to prepare himself, and it was only after passing the exam, that he could migrate.

One of the first bureaucratic contacts after his arrival was with the Educational Center for Integration where he was obliged to participate in the integration course. Again, he felt stressed because of the additional exams that he had to pass in order to obtain a residence permit. However, he was very positive regarding his bureaucratic contacts. He attributed this mainly to his so-called 'integration coach' who was assigned to him by the municipal authorities. This coach informed him constantly about 'how things work here'. The motivation of the migrant to learn the language and to find a job as soon as possible struck the coach, who helped him as much as he could. His motivation reflected for example in the fact that he daily practiced the Dutch language with his wife and made a lot of progress in a short period of time. In addition, even though he was not able to speak the Dutch language flawlessly, with the help of his wife he would write many application letters. Consequently, his coach responded by introducing him to various potential employers and he even managed to convince the municipality to reward his motivation and commitment by granting him training as a security guard. The support of his integration coach had a positive impact on the migrant, es pecially in terms of his opportunities on the labor market. Moreover, the fact that the authorities adopted a flexible attitude towards the times at which the migrant could attend his classes made it possible for him to develop a healthy work-life balance. In this case, the contact with the bureaucracy has thus led to more commitment and motivation from the migrant to integrate.

While we have presented a number of pathways that appear more frequently in our data, we want to caution the reader for assuming that these particular pathways apply to the whole population. Each immigrant had to deal with a series of bureaucratic contacts. Some of those contacts were follow-ups on the immigration and integration process but in other instances the contacts concerned different matters, e.g. a legal dispute about the permits required to run a Chinese restaurant. Ostensibly, such contacts appear outside the realm of immigration and integration but in the eyes of the respondents, this was not the case. They considered all bureaucratic contacts as part of their process of immigration and 
integration. We consider these strings of contacts as part of the same feedback loops we aim to uncover because the respondents appear to regard them as such and act accordingly.

\section{Feedback Loops Identified}

We used the reconstruction of the various pathways to identify feedback loops. We will discuss the archetypes here. Again, the examples are not exhaustive but serve as an illustration of such loops. First of all, we found that various effects can be traced back to the period when the migrant just settled in the Netherlands. Bureaucratic contacts in that first stage are very important for the attitude, perception and behavior of the migrant towards the government and its policies for the remaining period of time. In other words, this period is often decisive for the 'successful integration' of migrants, meaning the perceived success as defined by migrants themselves. We refer to this period as 'the reset-phase', when migrants try to find their new ways of life in the host society whilst at the same time retaining or discarding elements associated with the country of origin.

The data shows unambiguously that the lives of migrants in their home country differ greatly from their lives in this particular period. Feedback loops occur when the migrant experiences a form of opposition of bureaucrats in the reset-phase. The (perceived) bureaucratic adversity can lead to little change in the situation of the migrant despite considerable effort to build a life in the Netherlands. The relationship between the Iranian refugee and the counselor working at the Center for Refugees, mentioned above, serves as a good example. The migrant tried her best to succeed in Dutch society, but she felt her counselor, didn't support her in these ambitions and advised her to find an arbitrary job as soon as possible. In the eyes of this particular migrant, integrating in the new society was more than 'finding an arbitrary job': it was about working to your full potential. And this was actually what she felt was being counteracted by the public officials she engaged with. More importantly, the migrant lost her trust in the Dutch authorities, and hence in the bureaucratic system as a whole. That her diplomas weren't being recognized by the Dutch government reinforced these negative feelings. She therefore chose to resign in her fate. The following quote exposes part of the migrant's mental construct regarding the workings of the bureaucratic system:

"I tried my best to learn the language and to contribute to and engage in Dutch society...I did everything I could to find a good job, but nobody really cared about my ambitions, the only thing they did is throw obstacles in my search for a better life. (Interview Iran refugee, 2012).”

Eventually, it was her adaptation to (her understanding of) the workings of the bureaucracy, that led to little change in her work and life. Other cases also show that the bureaucracy is perceived as a major obstacle to rebuild a life, for example when legislation prevents migrants from working. For example, an Albanian migrant obtained a residence permit because of a job transfer. After a number of years, he decided to start his own business. However, legislation put demands on starting businesses that the migrant thought were unrealistic and that he could not meet. The first years, he nevertheless attempted to follow his ambition by actively engaging with local government officials to discuss the situation. At a certain point however, the migrant felt that no one was willing to facilitate what he felt 'successful integration' is about: contributing to society by finding a job that suits your talents. As a result, he gave up and developed much resentment towards the bureaucracy. In both cases, we witness a negative feedback loop with an unfavorable effect because it nullifies attempts to get through the reset phase and build a new life (figure 1).

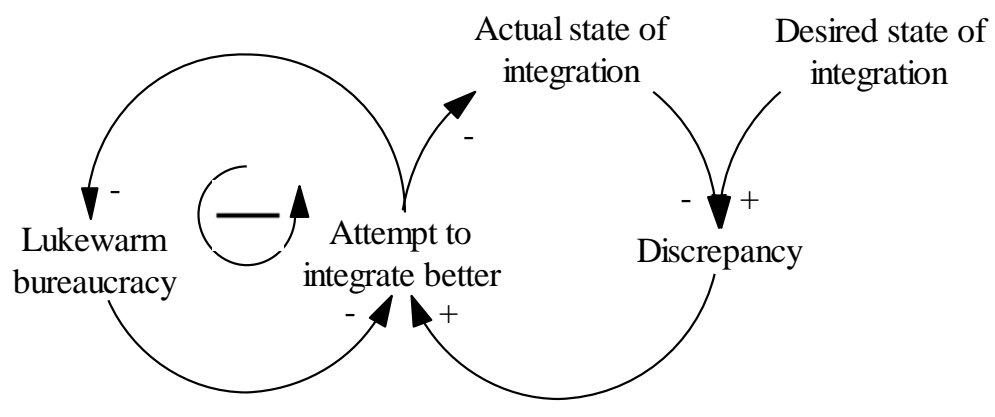

Figure 1. Set of negative feedback loops where the actual state of integration doesn't change due to perceived lukewarm responses from the bureaucracy when migrants try to integrate 
The simple loop shown in figure 1 only applies to the reset phase. Obviously, the polarity of the feedback loops can shift between negative and positive, depending on the time frame taken into account. In some cases, it may take a long time to emerge. A good example of this is a Turkish respondent who migrated in the 1970s. For most of his residence in the Netherlands, the government didn't contact him at all. This lack of contact now makes him feel indifferent towards the recent position of government when it comes to integration issues. In his view - just as in the view of the earlier mentioned Moroccan couple that migrated in the 1970s - the same government that never had invested in them is now putting demands on them to become 'full' citizens and participate more actively in society. For this migrant - as for many others - he succeeded in integrating into society by "taking his responsibilities" and finding a job to provide for his family. He emphasizes that he is the one who made the efforts to build a "home" in the Netherlands: he did not lean on the government to help or support him in any way- and as a result he believes that the government should not suddenly interfere with his current live. As the following quote shows, this led to resentment and eventually to withdrawal:

"As a son of a "guest worker", nobody placed any demands on my stay in this country. I was invisible for them. Everything that I have accomplished is a result of my own hard working. I don't really blame the government, but in those days nobody guided you in the new society that we were part of. So now, I'm just focusing on my own life, my children, my work ...I don't really care about what they have to say about us (Interview Turkish respondent, 2012)."

Lack of contact with the Dutch bureaucracy in the reset-phase seems thus to be used by migrants to evaluate the current integration policies, and the obligations that result from them. Here, a positive feedback loop returns unfavorable effects and no change in the migrants' lives (figure 2).

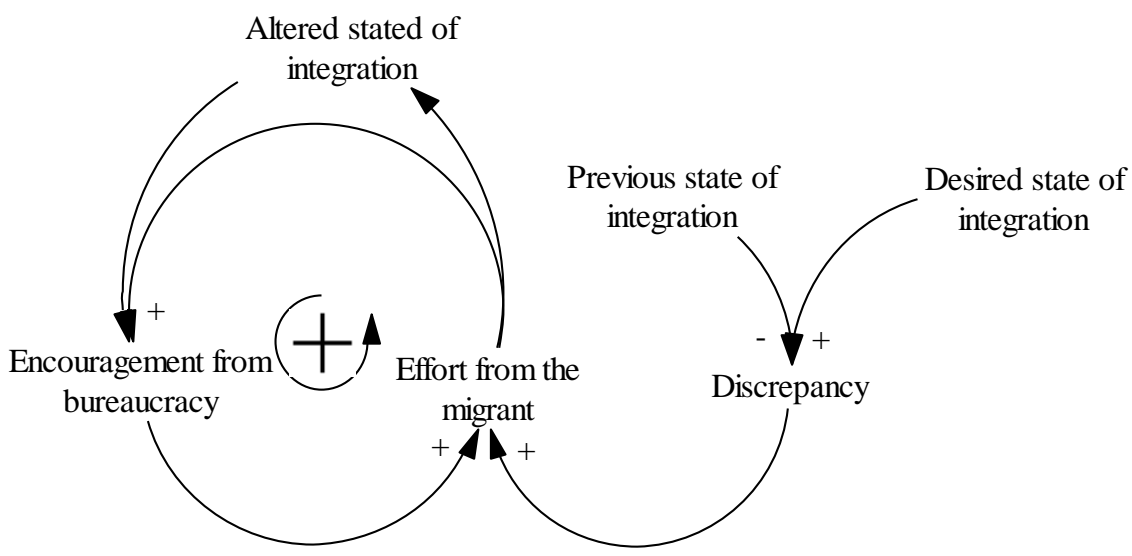

Figure 2. Set of feedback loops where lack of engagement from bureaucrats in the past leads to resentment on behalf of the migrant, in turn leading to a stronger push from the bureaucracy, which leads to more resentment; in other words: a self-reinforcing loop resulting in no change to the actual state of integration as a result

We also identified positive feedback loops that lead to both unfavorable and favorable changes, i.e. loops that cause major changes in the migrants' situations. In the cases of favorable effects, we noticed that there often was a counselor or coach involved, who helped the migrant in his attempts to participate the host society. The reasoning of the Moroccan migrant who we mentioned before - exemplifies this very well:

"Inoticed that my coach really was impressed by my attempts to settle in the Netherlands, especially in finding a good job and learning about how things work in this country...I wanted to participate in my new home land in all possible ways, and I'm so happy that I got rewarded for that, It only stimulates me to work even harder" (Interview Moroccan respondent, 2012).

The process was hence self-reinforcing where effort lead to success, in turn leading to more efforts and consequent success (figure 3). Interestingly, also in this particular case the migrant referred to successful integration as "making a living", "taking care of your family" and by doing so "one is contributing to a healthy society". 


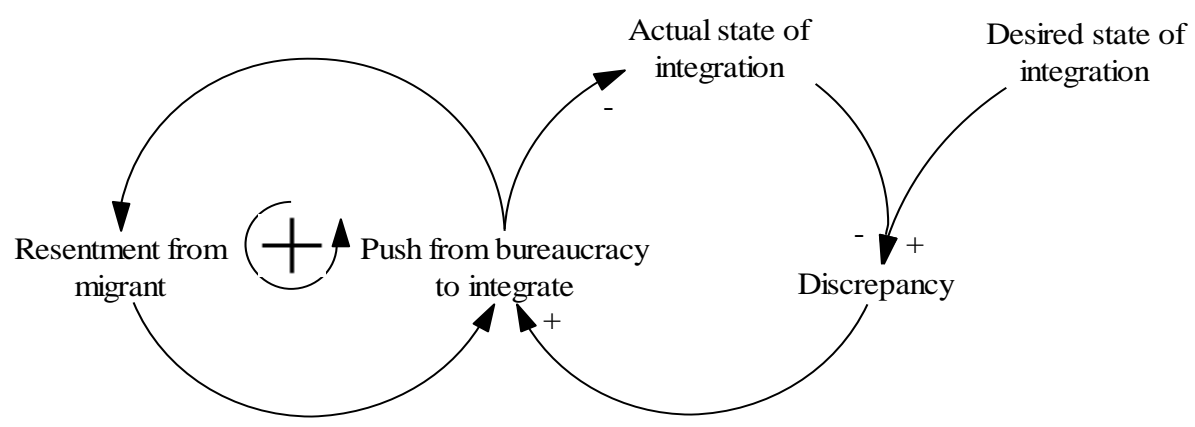

Figure 3. Set of positive feedback loops that where efforts from the migrant to integrate are met with encouragement and facilitation from the bureaucracy, which leads to more efforts from the migrant, resulting in better integration, which again leads to more encouragement from the bureaucracy

In other cases, however, we noted major change due to contacts inside and outside of the immigration bureaucracy but with unfavorable implications for migrants. This unfavorable change in turn influenced the willingness of migrants to integrate in Dutch society and their complete lives. For example, a migrant from Bangladesh had to fill in several documents in order to obtain a permit for his wife. Because this couple had started their own restaurant - and therefore had to arrange their own tax-related matters - they couldn't gather and provide the information within the prescribed period. As a result, the Immigration Department started a lawsuit against them, in which it demanded that the residence permit would be revoked. The lawsuit lasted for years before finally the court ruled in favor of the migrants. However, the costly lawsuit meant that they had to fire most of the restaurant staff. Consequently, the migrant could no longer be a stay-at-home mother but was forced to work on a full-time basis. As the following quote illustrates:

"After everything that happened, I just wanted to live my life in peace...running my own business with my husband, spending time with my family... I no longer feel at home here and don't want to invest any time in learning about this new society that robbed me from a lot of time and money... and even more important my peace of mind." (Interview Bangladeshi respondent, 2012).

The uncertain legal situation had a major impact on the emotional wellbeing of the migrant, eventually leading to much resentment towards the Dutch government (figure 4).

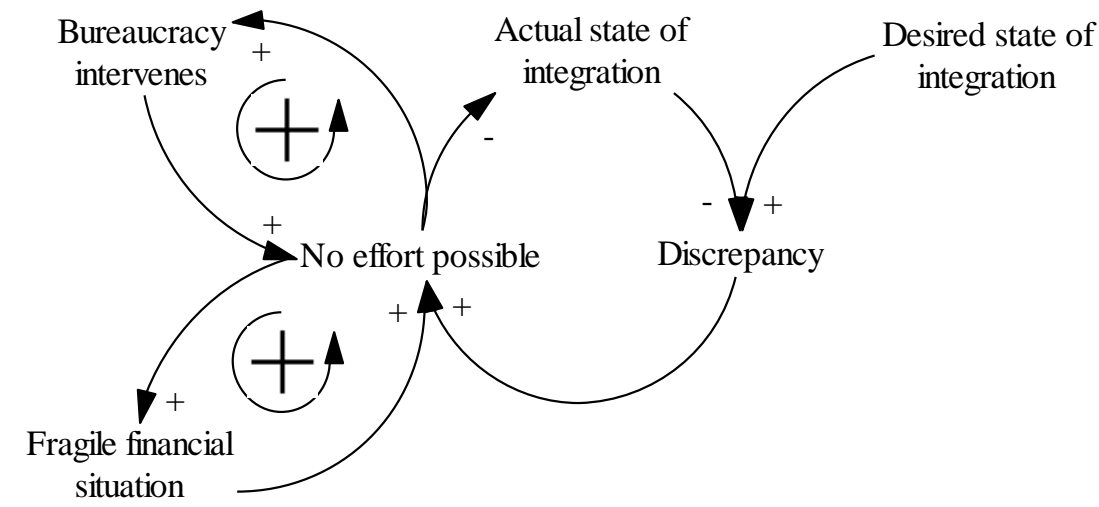

Figure 4. Example of set of two positive feedback loops with an unfavorable result where environmental conditions (such as a fragile personal or financial situation) reinforce resentment and inability to comply with bureaucratic demands

Another example, concerns a Moroccan migrant, who entered the country in the 1990s, in the context of family reunification. After a couple of years he divorced his wife. Because he did not possess a permanent residence permit yet, the Immigration Department informed him that his residence in the Netherlands had lost its legal basis. The migrant started a lawsuit against the Department that lasted for almost 8 years. Eventually, the court ruled in his favor. Nevertheless, the situation had already impacted his life. Because he was (legally) not allowed to work for 8 years, he decided to do undeclared work in different factories. Furthermore, he no longer felt connected with the host country and lost all his trust in the authorities. In other words: the relationship between response and input seems to be disproportional. These examples again prove that "successful" integration for these migrants is not that complicated: it simply is about being able to make a living, take responsibility for your family, and "standing on your own feet". As appeared in most of the previous examples, bureaucratic contact can affect the attitude towards the Dutch go vernment or society as well as the actual willingness of the migrant to conform to integration demands from the government. This in turn impacts the way bureaucrats are approached, who will respond accordingly. A reinforcing loop emerges as a consequence. 


\section{Patterns Identified}

The data shows a wide variety of feedback loops with both expected and surprising, favorable and unfavorable outcomes. Surprises encompass the fact that some loops cross the very raison d'être of specific integration policies (cf. policy resistance, Meadows \& Wright, 2008). For example, some migrants choose to participate in an integration course on a voluntary basis. A little later, the integration policies changed and the municipality then attempted to let them pass the integration exam. This well-intended incentive to change something in the integration system set-off a chain of unintended effects including mutual distrust and unwillingness to put further effort in the integration process. Conversely, the support of a counselor or coach could cause a self-reinforcing cascade of successful adaptations to the new situation. Each indi vidual story thus embodies a set of feedback loops that help explaining the constraints and catalysts of successful integration.

In more than half of the individual stories of respondents, there exists at least one negative feedback loop with an unfavorable impact on the life of the migrant. One of the most common negative feedback loops occurs when the migrant has had little contact with the bureaucracy. In other cases, migrants showed much commitment and motivation to participate in the new society, but the lack of bureaucratic involvement or support led to strong resentment towards the government. Again, we would like to emphasize that the reset-phase is very important for migrants in setting the foundation for further integration. They seem to use this period to evaluate the current integration policies and the obligations that result from them. In understanding the constraints and catalysts of successful integration (policies), we therefore should be aware of the effects that stem from this particular phase. It seems that those effects - on both the willingness as the chances of migrants to succeed in the new society - can persist in the long-term because of self-reinforcing or self-defeating loops that follow from that stage.

We would like to point out that positive and negative feedback often co-occur in the stories of the migrants. An example is that of the above-mentioned bureaucratic contact between the Moroccan migrant and the integration coach, who eased his entry in Dutch society. The migrant developed a mini-theory about how the systemic whole works and about what he needed to do to get more help. Eventually, his contact with the coach led to more motivation and commitment. At the same time, the driver's license that he used in his home country wasn't acknowledged by the Dutch authorities. Consequently, the chances of work at a greater distance from home diminished. This in turn led to feelings of resentment towards the government, which could have slowed down his efforts. In this case, the support of his coach out-weighted the dampening effect of other bureaucratic contacts. In addition, it sometimes appeared that the same bureaucratic contact triggered different feedback loops with both favorable and unfavorable effects. For example, a Ghanaian migrant experienced her integration course as emotionally very stressful. As a result of the pressure to pass the exams, she felt resentment towards the bureaucracy. At the same time, she was very glad that the municipal authorities paid for her courses, thereby reducing the financial burden and giving her the opportunity to increase her independency.

Looking at all the different individual pathways of migrants one thus notices that each of them is embedded in a specific context with specific local conditions. These differences constitute the main pattern here. In other words: where regulations are built on the assumption that there is a strictly limited set of pathways or bureaucratic trajectories and that each immigrant will follow one of them, leading to predefined outcomes, reality shows that each migrant follows an entirely specific pathway that is shaped by local conditions and that may to a bigger or lesser extent be different from the pathways of other migrants, even from those that are seemingly in the same category. Furthermore, the integration pathways that we identified were independent of the time period that migrants settled in the Netherlands. This downplays the simplistic cause-and-effect relationships that frequently are used to explain the failure or success of immigrant integration and that assume certain outcomes based on specific policies. Altogether, we note that bureaucratic decisions regarding integration policies will trigger different feedback loops, producing intended and unintended results that can be both favorable and unfavorable for successful migrant integration.

\section{Conclusions}

We aimed to explain the relative successes and failures of integration policies in the Netherlands by reconstructing the sets of feedback loops between immigrants and bureaucracy. We interviewed 51 immigrants from different backgrounds. The data showed that bureaucratic contacts or lack of such contacts reinforce or dampen the extent of integration. Acouple of contacts with favorable results will lead to a positive attitude of bureaucrats because the migrant seems to do well, which in turn gives them an incentive to go the extra mile for this person. However, we also noted the occurrence of a vicious circle of disappointment and unfavorable consequences, sometimes leading the immigrants to completely give up their attempts to integrate in the Dutch society. Other combinations of positive or negative loops with favorable or unfavorable consequences have also been observed.

If we accept that the extent of integration of migrants in society is reinforced or dampened through bureaucratic contacts of any kind, we start to get an idea of the systemic properties of the issue and its resilience against attempts to have an 
influence on it. Policies, by their very nature, address a single component of the systemic whole and risk isolating the current attitudes and behaviors of migrants from their indispensable past. Or as Sterman (2006) correctly observes: "policy resistance arises because we do not understand the full range of feedbacks surrounding - and created by - our decisions" (p. 507). The importance of the 'reset phase' illustrates this. Bureaucratic contacts - or lack thereof - that take place in this particular period are used by migrants to evaluate their position in the new situation and the obligations and right arising from it. Dampening and reinforcing reactions of the bureaucracy impact both the willingness as well as the chances of the migrant to succeed in the host society. Changing a particular policy will therefore not necessarily change the system as a whole. Eventually, the willingness of migrants to take the necessary steps to successful integration is the result of the cumulative effects of all these feedback loops. Moreover: for many migrants 'successful integration' mainly revolved around 'making a living', 'stand on your own feet', and 'building a new life for your family'. It was not necessarily connected to specific government demands regarding language or social-cultural norms, rather it was linked to a mission of finding a new 'home'. Bureaucratic contacts that were experienced as an obstacle or facilitator to this mission were hence used at a later stage to evaluate specific obligations that derive from integration policies.

This study has attempted to go beyond the truism that migration and integration - like as many other policy fields - are complex. We have attempted to show the feedback mechanisms that drive integration processes. While for scholars well-versed in system dynamics it may be obvious that the feedback structures - linking previous and current actions and decisions - are pivotal in understanding social reality, only few studies actually unravel the actual dynamics of feedback in implementing public policies. As Sterman (2006) argues: scientific methods are necessary to expose our hidden assumptions and biases that underlie systems. This is in particular true for the literature on migration and integration, which has paid very less little attention to the systemic reality in which willingness and resentment towards bureaucracies develop, in turn preventing full understanding of migrant attitudes as well as their chances to succeed the country of destination. Our system approach has hence enabled us to see the underlying structure that produces certain behavior, in this case: the behavior of immigrants towards bureaucracy and vice versa. While it cannot be expected from individual policy makers to oversee the systematic whole of interrelated situations and actions, our work does invite one to challenge existing mental models, in which failure of integration policies is reduced to a problem of migrants (unwillingness to comply) or a government problem ("too soft" policies). In addition, policy implementers - often: street-level bureaucrats - should be aware that their clients are the result of result of the cumulative effects of many reinforcing and dampening interactions with bureaucracy (e.g. Belabas \& Gerrits, 2016). Hence, implementers should be cautious in evaluating behavior or actions from migrants only based on the 'isolated' piece of reality that they are seeing.

As a final reflection, the research also calls into the question whether a truly systemic policy or a policy that manages to factor in all elements of integration would be feasible. The history of policy-making has shown that attempts at cybernetic policies have failed to deliver the proverbial 'control switch that was expected to control society (see e.g. Klijn \& Snellen 2009, for an extended discussion). We concur. The data shows such a wild variety of issues and such a complex entanglement of feedback loops that it would be naï ve to expect there to be one set of relations that govern society. If anything, immigrants and bureaucrats act local in place and temporal in time. Each contact and decision bears a certain degree of randomness that comes with bureaucratic delegation and that means that policies are not applied mechanically anyway (cf. Belabas \& Gerrits, 2016). As Lipsky (1980) argues, bureaucrats are in a constant search between compassion and flexibility on the one hand and impartiality and rigid rule-application on the other, resulting in a number of conscious or subconscious coping strategies. As such, these dynamics defy the possibility of an all-encompassing, systemic policy. We would argue that an effective policy approach to integration would have to center on tailor-made decisions that take as much situational information into account as possible. This is quite the opposite of the drive towards simplified policies and protocols that is now popular in the Netherlands. At the same time, we can imagine that more situational information can make it harder for those working with migrants to arrive at their decisions. Resolving these tensions perhaps requires some degree of balancing between both extremes.

\section{References}

Belabas, W., \& Gerrits, L. (2015). Going the extra mile? How street-level bureaucrats deal with the integration of immigrants. Social Policy \& Administration, 51 (1), 133-150. https://doi.org/10.1111/spol.12184

Benish-Weisman, M., \& Horenczyk, G. (2010). Cultural identity and perceived success among Israeli immigrants: an emic approach. International Journal of Intercultural Relations, 34, 516-526. https://doi.org/10.1016/j.jintrel.2009.11.010

Berg, B. L., \& Lune, H. (2004). Qualitative research methods for the social sciences. Pearson: Boston, MA.

Berry, J. W. (1997). Immigration, acculturation, and adaptation. Applied psychology, 46, 5-34. https://doi.org/10.1111/j.1464-0597.1997.tb01087.x

Berry, J. W., Phinney, J. S., Sam, D. L., \& Vedder, P. (2006). Immigrant youth: acculturation, identity, and adaptation. 
Applied psychology, 55, 303-332. https://doi.org/10.1111/j.1464-0597.2006.00256.x

Boom, J. de, Weltevrede, A., Seidler, Y., van Wensveen, P., Snel, E., \& Engbersen, G. (2010). Migration and migration policies in the Netherlands 2010. Dutch SOPEMI-Report 2010. Retrieved from: http://www.godfriedengbersen.com/wp-content/uploads/sopemi-2010.pdf

Buijs M. J., Eshuis, J., \& Byrne, D. S. (2009). Approaches to researching complexity in public management. In G.R Teisman, A. Van Buuren, L.M. Gerrits (Eds.), Managing complex governance systems: Dynamics, self-organization and coevolution in public investments (pp. 37-55). New York: Routledge.

Byrne, D. S., \& Ragin, C. C. (2009). The Sage handbook of case-based methods. Sage Publications Ltd: London. https://doi.org/10.4135/9781446249413

Byrne, D. S. (2005). Complexity, configurations and cases. Theory, Culture \& Society, 22, 95-111. https://doi.org/10.1177/0263276405057194

Checkland, P. (1981). Systems thinking, systems practice. John Wiley \& Sons: New York.

Churchman, C. W. (1979). The systems approach and its enemies. Basic Books: New York.

Clarke, D. D., \& Crossland, J. (1985). Action systems: An introduction to the analysis of complex behavior. Methuen: London.

Crul, M., \& Schneider, J. (2010). Comparative integration context theory: participation and belonging in new diverse European cities. Ethnic and racial studies, 33, 1249-1268. https://doi.org/10.1080/01419871003624068

Duyvendak, J. W., \& Scholten, P. W. (2011). Beyond the Dutch “multicultural model”. Journal of international migration and integration, 12(3), 331-348.

Entzinger, H., \& Biezeveld, R. L. (2003). Benchmarking in immigrant integration. European Research Centre on Migration and Ethnic Relations, Erasmus University Rotterdam.

Entzinger, H. (2006). Changing the rules while the game is on: From multiculturalism to assimilation in the Netherl ands. In Y.M Bodemann, G. Yurdakul (Eds.), Migration, Citizenship, Ethnos: Incorporation Regimes in Germany, Western Europe and North America, (pp. 121-144). New York: Palgrave MacMillan. https://doi.org/10.1057/9781403984678_7

Flood, R. L. (1999a). Rethinking the fifth discipline: learning within the unknowable. Routledge: London.

Flood, R. L. (1999b). Knowing of the unknowable. Systemic Practice and Action Research, 12, 247-256. https://doi.org/10.1023/A:1022447617323

Joppke, C. (2007). Beyond national models: Civic integration policies for immigrants in Western Europe West European Politic, 30, 1-22.

Kasinitz, P., Mollenkopf, J., Waters, M., \& Holdaway, J. (2008). Inheriting the city. The children of immigrants come of age. Russell Sage Foundation Books: Harvard University Press.

Kim, H., \& Andersen, D. F. (2012). Building confidence in causal maps generated from purposive text data: mapping transcripts of the federal reserve. System Dynamics Review, 28, 311-328. https://doi.org/10.1002/sdr.1480

Klijn, E. H., \& Snellen, I. (2009). Complexity theory and public administration: a critical appraisal. In G.R. Teisman, A. Van Buuren, M.L. Gerrits (Eds), Managing Complex Governance Systems: Dynamics, Self-organization and Coevolution in Public Investments (pp. 17-36), London: Routledge.

Koopmans, R. (2003). Good intentions sometimes make bad policy. A comparison of Dutch and German Integration Policies, In R. Cuperus, K.A. Duffek, J. Kandel (Eds.), The Challenge of Diversity. European Social Democracy Facing Migration, Integration, and Multiculturalism (pp. 163-168), Innsbruck: StudienVerlag.

Korac, M. (2003). Integration and how we facilitate it: Acomparative study of the settlement experiences of refugees in Italy and the Netherlands, Sociology, 37(1), 51-68. https://doi.org/10.1177/0038038503037001387

Lipsky, M. (1980). Street-level bureaucracy: dilemmas of the individual in public services. Russell Sage Foundation: New York.

Meadows, D. H., \& Wright, D. (2008). Thinking in systems: A primer. Chelsea: Green publishing.

Mjøset, L. (2009). The contextualist approach to social science methodology, In D.S Byrne \& C.C Ragin (Eds.), The sage handbook of case-based methods (99. 39-68), London: Sage.

Montgomery, J. R. (1996). Components of refugee adaptation. International Migration Review, 679-702. https://doi.org/10.2307/2547632 
Penninx, R., Garces-Mascarenas, B., \& Scholten, P. (2006). Policymaking related to immigration and integration: a review of the literature of the Dutch case. Country report of the Netherlands. Retrieved from http://dare.uva.nl/document/39852

Poppelaars, C., \& Scholten, P. (2008). Two worlds apart: The divergence of national and local immigrant integration policies in the Netherlands. Administration \& Society, 40(4), 335-357. https://doi.org/10.1177/0095399708317172

Richardson, G. P. (2011). Reflections on the foundations of system dynamics. System Dynamics Review, 27, $219-243$. https://doi.org/10.1002/sdr.462

Scholten, P. W. A., \& Van Nispen, F. K. M. (2008). Building bridges across frames? Journal of Public Policy, $28,181-205$. https://doi.org/10.1017/S0143814X08000846

Sterman, J. D. (2006). Learning from evidence in a complex world. American journal of public health, 96, 505-514. https://doi.org/10.2105/AJPH.2005.066043

Strauss, A., \& Corbin, J. (1990). Basics of qualitative research. Newbury Park, CA: Sage.

Strauss, A., \& Corbin, J. (1994). Grounded theory methodology. Handbook of qualitative research, 17, $273-285$.

Ulrich W. (1988). Systems thinking, systems practice, and practical philosophy: A program of research. Systems Practice, 1, 137-163. https://doi.org/10.1007/BF01059855

Vasta, E. (2007). From ethnic minorities to ethnic majority policy: multiculturalism and the shift to assimilationism in the Netherlands. Ethnic and Racial Studies, 30, 713-740. https://doi.org/10.1080/01419870701491770

Wagenaar, H. (2007). Governance, complexity and democratic participation: How citizens and public officials harness the complexities of neighborhood decline. The American Review of Public Administration, 37, 17-50. https://doi.org/10.1177/0275074006296208

\section{Copyrights}

Copyright for this article is retained by the author(s), with first publication rights granted to the journal.

This is an open-access article distributed under the terms and conditions of the Creative Commons Attribution license which permits unrestricted use, distribution, and reproduction in any medium, provided the original work is properly cited. 